Jurnal

Kardiologi Indonesia

J Kardiol Indones. 2013;34:48-54

ISSN $0126 / 3773$

\title{
Selection of Balloon Mitral Valvuloplasty Candidate in Rheumatic Mitral Stenosis
}

Amiliana M Soesanto

Department of Cardiology and Vascular Medicine, Faculty of Medicine, University of Indonesia, and National Cardiovascular Center Harapan Kita
Balloon Mitral Valvulotomy (BMV), sometimes also referred to as Percutaneous Transcatheter Mitral Commissurotomy (PTMC) is becoming a common treatment option for patients with mitral stenosis. Compared to surgical valvotomy, it has less procedural risk, shorter hospital stay and comparable outcome. However, that good result can only be achieved in selected good candidates. This article will give a highlight of some consideration to choose a good candidate for BMV mostly evaluated by echocardiography.

(J Kardiol Indones. 20 I3;34:48-54)

Keywords: patient selection, balloon mitral valvulotomy 


\title{
Seleksi Kandidat Balloon Mitral Valvuloplasty pada Stenosis Mitral Rematik
}

\author{
Amiliana M Soesanto
}

\begin{abstract}
Valvulotomi katup mitral perkutan (BMV) merupakan pilihan terapi yang umum bagi pasien stenosis mitral. Dibandingkan valvotomi secara pembedahan, BMV memiliki risiko yang lebih kecil, masa rawat yang lebih singkat, dengan hasil yang sebanding. Namun demikian, hasil yang baik akan dapat dicapai dengan pemilihan kandidat yang baik untuk tindakan tersebut. Artikel ini memberika ulasan singkat mengenai beberapa pertimbangan memilih kandidat BMV yang sebagian besar dilakukan dengan pemeriksaan ekokardiografi.
\end{abstract}

(J Kardiol Indones. 2013;34:48-54)

B alloon Mitral Valvotomy (BMV), yang disebut juga sebagaiPercutaneous Transcatheter Mitral Commissurotomy (PTMC)merupakan pilihan tatalaksana untuk pasien dengan stenosis mitral. Dibandingkan denganpembedahan valvotomi, BMV memiliki risiko yang lebih rendah, lama perawatan di rumah sakit yang lebih pendek, namunhasil yang sebandingdenganpembedahan valvotomi. Faktor yang penting untuk mendapatkan hasil yang baik dengan luaran klinis yang baik dari tindakan BMV adalah seleksi kandidat yang tepat.

Alamat Korespondensi:

Dr. dr. Amiliana M Soesanto, SpJP. Departemen Kardiologi dan Kedokteran Vaskuler FKUI dan Pusat Jantung Nasional Harapan, Kita, Jl. S. Parman Kav. 87 Jakarta I|420, E-mail: amilianal4@ gmail.com
Dalam memilih kandidat yang baik untuk intervensi khususnya BMV, beberapa faktor harus dipertimbangkan antara lain; waktu intervensi, morfologi katup mitral, trombus dalam atrium kiri, kelainan katup lain, dan penyakit penyerta. Faktor-faktor tersebut dapat dideteksi secara detail melalui pemeriksaan ekokardiografi.

\section{Waktu untuk Intervensi Berdasarkan Karakteristik Klinis}

Intervensi bedah maupun non bedah adalah terapi definitif pada stenosis mitral. Waktu dan tipe intervensi bedah atau perkutan secara umum ditentukan berdasarkan karakteristik klinis dan morfologi katup.Panduan tatalaksana stenosis mitral dari Euro- 
pean Society of Cardiology 2012 merekomendasikan bahwa secara umum intervensi untuk stenosis mitral perlu mempertimbangkan beberapa hal antara lain derajat stenosismitral (MVA $\left.<1.5 \mathrm{~cm}^{2}\right)$, gejala klinis, risiko tromboemboli dan gangguan hemodinamik (al;hipertensi pulmonal dan atau atrial fibrilasi), risiko operasi dan morfologi katup. ${ }^{1,2}$ Gambar 1 memperlihatkan algoritme waktu untuk intervansi pada stenosis mitral. Waktu untuk tindakan BMV dapat dilakukan lebih awal daripada pembedahan pada kandidat-kandidat yang sesuai. Prosedur BMV lebih disukai dibandingkan dengan operasi bila tidak ada kontra indikasi dan terpenuhi beberapa syarat yang dapat memprediksi hasil BMV yang sukses dan luaran klinis yang baik. Dari kepentingan klinis, penentuan severitas stenosis juga merupakan faktor yang penting dalam menetapkan kapan dilakukan intervensi.

\section{Peran ekokardiografi untuk menilai kandidat BMV}

Ekokardiografi memiliki peran yang amat penting untuk menilai kandidat BMV yang sesuai. Penilaian ekokardiografi mencakup penentuan derajat severitas stenosis, morfologi katup mitral, adanya regurgitasi mitral yang bermakna, adanya trombus, dan kondisi hemodinamik lain maupun kelainan katup lain yang menjadi pertimbangan tindakan tersebut.

\section{Penilaian morfologi katup mitral}

Keparahan deformitas katup mitral merupakan prediktor terhadap kesuksesan BMV. Prosedur BMV dikatakan sukses jika area katup mitral $>1.5 \mathrm{~cm}^{2}$ setelah prosedur, tanpa regurgitasi mitral yang lebih dari derajat 2 .

Skor Wilkins merupakan sistem skoring yang paling sering digunakan untuk menilai morfologi katup mitral untuk memprediksi suksesnya BMV. Beberapa sistem skoring lain adalah Cormier. Skor Wilkins menilai pergerakan katup, ketebalan katup, kalsifikasi, dan fusi subvalvar. ${ }^{3}$ Tabel 1 memperlihatkan penilaian skor Wilkins untuk masing-masing variabel. Bila skor total $\leq 8$, makin besar kemungkinan keberhasilan BMV dan memprediksi luaran yang baik, dengan sensitifitas $72 \%$ dan spesifisitas $73 \%$. ${ }^{4}$ Penggunaan skor Wilkins $\leq 8$ bila digabungkan dengan prediktor klinis ; usia $<45$ tahun, regurgitasi mitral $<$ grade 2
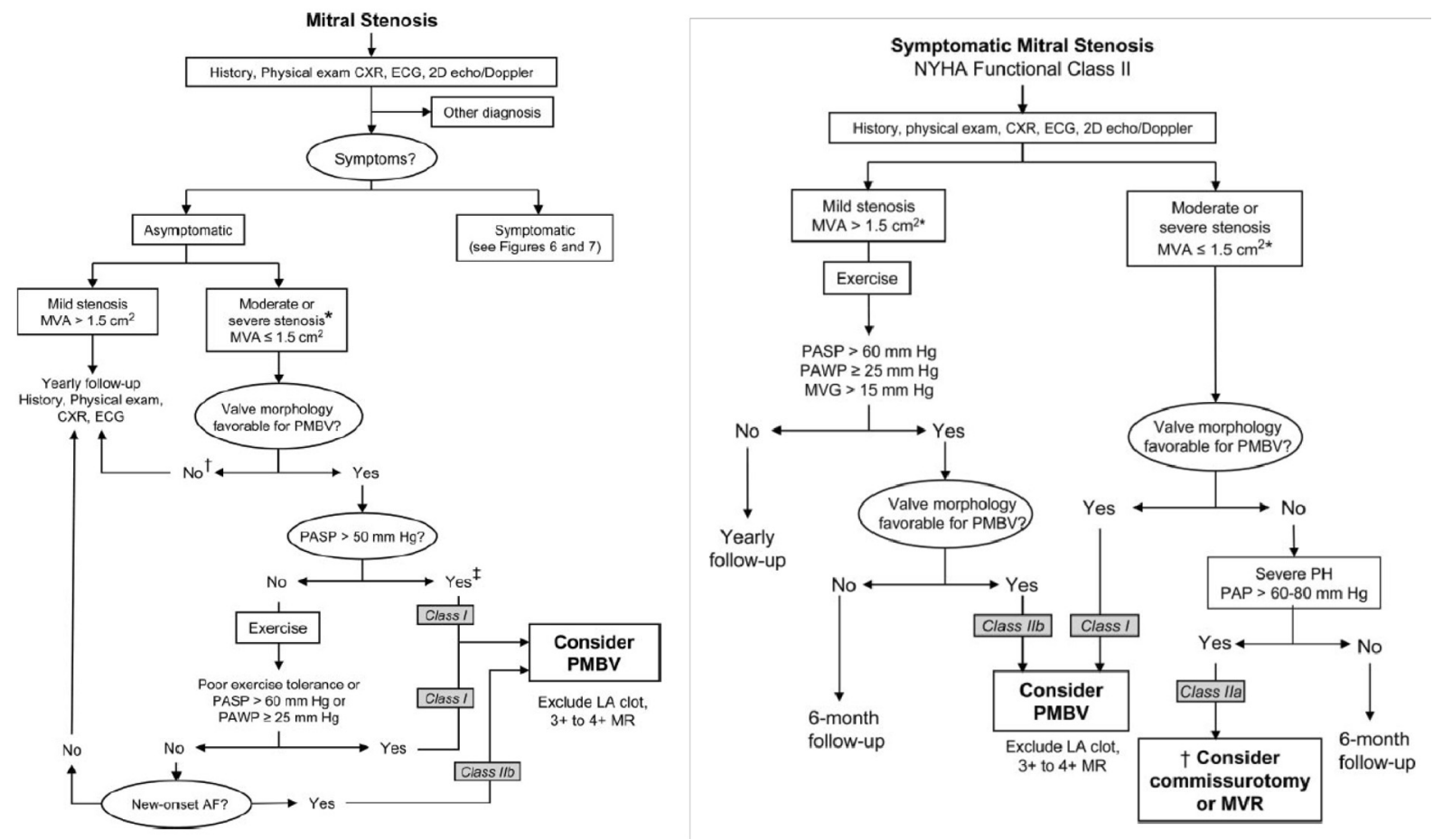

Gambar1. Strategi tatalaksana untuk pasien dengan stenosis mitral ${ }^{1}$ 
Tabel 1.Skor Wilkins untuk penilaian morfologi katup mitral pada stenosis mitral ${ }^{3}$

\begin{tabular}{|c|c|c|c|c|}
\hline Skor & ergerakan Katup & Ketebalan & Kalsifikasi & Ketebalan Subvalvular \\
\hline 1 & $\begin{array}{l}\text { erakan katup mobile dengan } \\
\text { gian ujung katup terhambat }\end{array}$ & $\begin{array}{l}\text { Ketebalan katup masih mendeka- } \\
\text { ti normal ( } 4-5 \mathrm{~mm}\end{array}$ & $\begin{array}{l}\text { Sebagian kecil area katup } \\
\text { dengan ekogenisitas yang } \\
\text { meningkat }\end{array}$ & $\begin{array}{l}\text { Penebalan pada daerah di } \\
\text { bawah katup }\end{array}$ \\
\hline 2 & $\begin{array}{l}\text { erakan katup normal pada } \\
\text { sal sampai dengan setengah } \\
\text { gian katup }\end{array}$ & $\begin{array}{l}\text { Bagian tengah katup normal, } \\
\text { penebaan ringan pada bagian } \\
\text { tepi }(5-8 \mathrm{~mm})\end{array}$ & $\begin{array}{l}\text { Iran area yang eko- } \\
\text { erbatas pada bagian } \\
\text { ip }\end{array}$ & $\begin{array}{l}\text { uktur kordae } \\
\text { ertiga bagian } \\
\text { e }\end{array}$ \\
\hline 3 & $\begin{array}{l}\text { Gerakan katup ke arah ventrikel } \\
\text { saat diastolik terutama bagian } \\
\text { basal }\end{array}$ & $\begin{array}{l}\text { Penebalan menyebar ke seluruh } \\
\text { bagian katup }(5-8 \mathrm{~mm})\end{array}$ & $\begin{array}{l}\text { Ekogenik yang meluas ke } \\
\text { bagian tengah katup }\end{array}$ & $\begin{array}{l}\text { Penebalan meluas ke seper- } \\
\text { tiga distal dari kordae }\end{array}$ \\
\hline 4 & $\begin{array}{l}\text { Tidak terdapat gerakan katup } \\
\text { atau gerakan yang minimal saja } \\
\text { pada saat diastolik }\end{array}$ & $\begin{array}{l}\text { Penebalan katup yang cukup } \\
\text { bermakna pada semua jaringan } \\
\text { katup }(>8-10 \mathrm{~mm})\end{array}$ & $\begin{array}{l}\text { Ekogenik yang meluas ke se- } \\
\text { bagian besar bagian katup }\end{array}$ & $\begin{array}{l}\text { Penebalan dan pemendekan } \\
\text { berat pada seluruh struk- } \\
\text { tur kordae meluas ke otot } \\
\text { papilaris }\end{array}$ \\
\hline
\end{tabular}

Skor total merupakan penjumlahan dari keempat variabel dengan rentang antara 4 sampai 16

pada pre-BMV, tidak ada riwayat operasi commissurotomy sebelumnya, dapat membantu untuk identifikasi pasien yang akan memperoleh luaran jangka panjang yang baik. ${ }^{5}$

Penilaian morfologi mitral dengan skor Wilkins rupanya dianggap masih belum cukup untuk mengidentifikasi pasien yang cocok untuk BMV. Mekanisme BMV adalah memisahkan komisura yang menyatu, sehinggafaktor lain yang dapat mempengaruhi hasil setelah BMV adalah keadaan komisura mitral. Suatu studi terhadap 300 pasien, mengelompokan luasnya kalsifikasi komisura men- jadi tingkat 0 sampai 4, dengan menggunakan short axis parasternal pada ekokardiografi transtorakal. Kesimpulannya menggambarkan bahwa derajat kalsifikasi komisura merupakan prediktor signfikan untuk mencapai area katup mitral $1,5 \mathrm{~cm}^{2}$ tanpa regurgitasi, terutama sekali pada pasien dengan skor Wilkins $\leq 8 .^{6}$

Sehubungan mekanisme BMV bertujuan memisahkan fusi komisura, ESCguidelines mengemukakan bahwa kalsifikasi berat komisura, kalsifikasi kedua komisura, dan sebaliknya tidak adanya fusi komisura merupakan kontraindikasi prosedur BMV. ${ }^{2}$

\begin{abstract}
Severe stenosis but no bright echos across either commissure

Grade: $0+0+0+0=0$
\end{abstract}

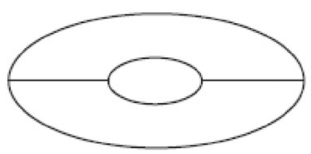

Bright echos extending across one half of posteromedial commissure

Grade: $1+0+0+0=1$

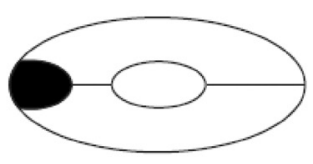

Bright echos extending throughout posteromedial commissure

Grade: $1+1+0+0=2$

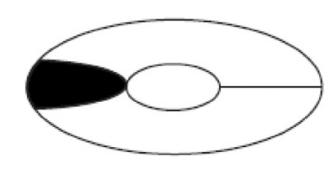

Bright echos across half of each commissure

Grade: $1+0+0+1=2$

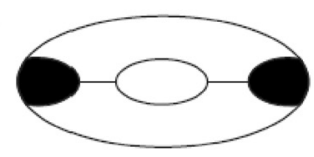

Bright echos across all of posteromedial and half of anterolateral commissure

Grade: $1+1+0+1=3$

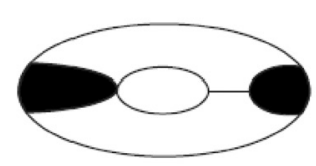

Gambar 2. Sistem grading kalsifikasi komisura. ${ }^{6}$ 


\section{Keberadaan trombus}

Pasien dengan stenosis mitral mengalami stasis darah akibat penyempitan area katup mitral maupun penurunan atau kehilangan fungsi kontraksi atrium. Hal tersebut dapat memicu pembentukan trombus dalam atrium kiri terutama bagian append age. Terdapatnya trombus atrium kiri merupakan kontraindikasi BMV, karena tindakan BMV dapat menimbulkan risiko lepasnya trombus selama prosedur. ${ }^{1,2}$ Terdapatnya trombus dapat dideteksi dengan ekokardiografi terutama ekokardiografi transesofageal (TEE).JikaTEE sebelum prosedur memperlihatkan adanya trombus atrium kiri, sebaiknya prosedur ditunda dan diberikan terapi antikoagulan selama beberapa bulan (target INR 3.0, dengan rentang $2.5-3.5$ ), sampai terjadi resolusi trombus yang dibuktikan dengan pengulangan TEE. Jika trombus atrium kiri tidak berhasil diatasi dengan antikoagulan, maka tindakan operasi merupakan pilihan yang lebih tepat. ${ }^{7}$

\section{Penyakit Katup Penyerta pada Katup Aorta dan atau Katup Trikuspid}

Etiologi stenosis mitral yang paling sering adalah proses reumatik. Proses reumatik dapat melibatkan lebih dari satu katup sehingga terjadi kelainan kombinasi (stenosis dan regurgitasi) pada satu atau lebih katup. Keterlibatan katup aorta bisa terjadi pada proses reumatik. Hipertensi pulmonal merupakan komplikasi yang sangat sering terjadi pada stenosis mitral. Trikuspid regirgitasi dapat timbul sekunder akibat hipertensi pulmoner maupun primer akibat proses rematik. Terdapatnya kelainan katup penyerta seperti ; regurgitasi mitral, regurgitasi aorta atau regurgitasi trikuspid dapat mempengaruhi pengambilan keputusan untuk melakukan BMV.

Prosedur BMV sebaiknya tidak dilakukan pada regurgitasi mitral signifikan. Guidelines ACC menbatasi BMV hanya pada stenosis mitral dengan regurgitasi mitral lebih kecil dari moderate-severe ${ }^{1}$, sedangkan guidelines ESC mengatakan bahwa regurgitasi mitral lebih dari mild merupakan kontraindikasi BMV. ${ }^{2}$

Derajat severitas regurgitasi trikuspid fungsional dapat membaik atau menetap tergantung dari hasil BMV. Masalahnya adalah bagaimana memprediksi penurunan derajat regurgitasi trikuspid pasca BMV tersebut. Sebuah penelitian dari 92 pasien, melaporkan bahwa pada pasien stenosis mitral severe dengan regurgitasi trikuspid fungsional severe, kombinasi antara operasi katup mitral dan reparasi katup trikuspid akan memberikan luaran jangka panjang yang lebih baik jika dibandingan dengan prosedur BMV saja. Hal ini menunjukkan bahwa regurgitasi trikuspid severe mempengaruhi luaran klinis pasien stenosis mitral sehingga harus diintervensi untuk memperbaiki prognosis terlebih lagi bila sudah disertai fibrilasi atrial dan dilatasi/penurunan fungsi ventrikel kanan. ${ }^{8}$ Pada keadaan tersebut BMV bukan merupakan pilihan terapi yang tepat. Pilihan ini bahkan lebih relevan bila terdapat regurgitasi trikuspid sedang atau berat dan bila anulus katup trikuspid $>40 \mathrm{~mm}$.

Beberapa pasien stenosis mitral reumatik juga mengalami regurgitasi aorta.Operasi katup aorta diindikasikan pada regurgitasi aorta yang berat, simtomatis dan/atau telah mengalami gangguan fungsi ventrikel kiri. Bagaimana pertimbangan BMV pada pasien stenosis mitral dengan regurgitasi aorta. Penelitian terhadap 676 pasien menunjukkan bahwa regurgitasi aorta pada saat prosedur BMV dilakukan, tidak mempengaruhi keberhasilan prosedur dan tidak berhubungan dengan luaran yang buruk. Hanya sebagian kecil pasien dengan stenosis mitral dan regurgitasi aorta moderate yang menjalani BMV memerlukan penggantian katup aorta di kemudian hari dalam follow up jangka panjang. ${ }^{9} \mathrm{Hal}$ ini menyimpulkan bahwa pasien dengan stenosis mitral dan regurgitasi aorta ringan atau sedang tetap menjadi kandidat yang baik untuk BMV.

\section{Kondisi khusus yang dapat mempenga- ruhi keputusan melakukan BMV}

Walaupun guidelines telah merekomendasi waktu yang tepat untuk intervensi, dan persyaratan yang sebaiknya dipenuhi untuk menghasilkan luaran yang baik pasca BMV, namun ada beberapa kondisi khusus yang dapat mempengaruhi keputusan melakukan BMV. Prosedur BMV bisa pada kasus pasien usia lanjut yang berisiko sangat tinggi terhadap operasi. Survival jangka panjang pasca BMV akan lebih rendah pada usia tua, terutama karena komorbiditas lain termasuk penyakit jantung koroner. Namun demikian, luaran dapat cukup baik terlebih bila pasien memiliki morfologi katup yang memenuhi syarat. Prosedur BMV juga efektif untuk tujuan paliatif,misalnya pada pasien usia lanjut dengan kondisi morfologi katup yang kurang ideal untuk BMV untuk hasil yang optimal, namun risiko 
operasi terlalu tinggi. ${ }^{10}$ Kondisi lain adalah keadaan emergensi yaitu pasien dengan henti jantung, edema pulmonal atau syok kardiogenik yang memerlukan tindakan segera untuk mengurangi tekanan atrium kiri. Dalam situasi ini, bila tidak terdapat trombus atrium kiri atau regurgitasi mitral moderate sampai severe, BMV dapat dilakukan dengan hasil mungkin suboptimal akibat kondisi morfologi katup yang kurang ideal.

Stenosis mitral sering didiagnosa pertama kali pada dekade ketiga atau keempat kehidupan, yang merupakan periode dimana sebagian besar perempuan berada pada masa reproduksi. Stenosis mitral pada kehamilan dapat menjadi masalah yang serius karena terdapatnya perburukan gejala yang diinduksi oleh beban hemodinamik pada kehamilan. Bila dengan istirahat total dan medikamentosa tidak berhasil memperbaiki keadaan klinis pasien, maka BMV dapat dilakukan dengan syarat tidak ada trombus atrium kiri/apendiks atrium kiri atau regurgitasi mitral moderate-severe. Waktu yang tepat untuk BMV pada pasien-pasien hamil adalah pada usia gestasi minggu ke-22 sampai minggu ke-26, karena pada waktu tersebut risiko radiasi kecil pada fetus. De Souza et al melaporkan bahwa keberhasilan tindakan prosedur BMV adalah 95\%. Mereka membandingkan BMV dengan open mitral commissurotomy dan mendapatkan bahwa komplikasi fetal lebih sedikit terjadi dan mortalitas fetal dan neonatal lebih rendah dengan BMV. (5\% vs $38 \%) .{ }^{11}$

\section{Penutup}

Prosedur BMV merupakan pilihan tatalaksana untuk pasien stenosis mitral karena memiliki risiko yang lebih rendah, lama perawatan di rumah sakit yang lebih pendek, namun hasil yang sebanding dengan pembedahan valvotomi. Faktor yang penting untuk mendapatkan hasil yang baik dengan luaran klinis yang baik dari tindakan BMV adalah seleksi kandidat yang tepat. Penilaian klinis, serta morfologi katup mitral dan hemodinamik yang dapat dinilai dengan ekokardiografi merupakan faktor yang utama dalam menseleksi kandidat BMV untuk prediktor keberhasilan BMV dan prognosis luaran jangka pendek maupun panjang yang baik. Sistem skoring, kondisi kalsifikasi komisura, diserta tanpa adanya trombus dan/atau regusrgitasi mitral yang bermakna menentukan kandidat BMV. Kelainan katup penyerta seperti misalnya regurgitasi trikuspid dan kelainan katup aorta yang bermakna merupakan faktor lain yang juga harus dipertimbangkan dalam memutuskan melakukan tindakan BMV. Pertimbangan yang seksama juga perlu dilakukan sebelum melakukan BMV pada kasus stenosis mitral usia lanjut, dalam kehamilan, dan kasus gawat darurat.

\section{Daftar Pustaka}

1. Bonow RO, Carabello BA, Chatterjee K, de Leon AC J, Faxon DP, Freed MD, et al. 2008 Focused Update in corporated into the ACC/AHA 2006 Guidelines for the Management of Patients With Valvular Heart Disease. Circulation 2008; 118: e523 - e 661.

2. Vahanian A, Alfieri O, Andreotti F, Antunes MJ, Esquivias GB, Baumgartner $\mathrm{H}$, et al. Guidelines on the management of valvular heart disease (version 2012). The Joint Task Force on the Management of Valvular Heart Disease of the European Society of Cardiology (ESC) and the European Association for Cardio-Thoracic Surgery (EACTS). Eur Heart J. 2012.

3. Wilkins GT, Weyman AE, Abascal VM, Block PC, IF P. Percutaneous balloon dilatation of the mitral valve: an analysis of echocardiographic variables related to outcome and the mechanism of dilatation. Br Heart J 1988; 60: 299-308.

4. Abascal V, Wilkins G, O'Shea J, Choong C, Palacios I, Thomas $\mathrm{J}$, et al. Prediction of successful outcome in 130 patients undergoing percutaneous balloon mitral valvotomy. Circulation. 1990; 82: 448-56.

5. Palacios I, Sanchez P, Harrell L, Weyman A, Block P. Which Patients Benefit From Percutaneous Mitral Balloon Valvuloplasty?: Prevalvuloplasty and Postvalvuloplasty Variables That Predict Long-Term Outcome. Circulation. 2002; 105: 1465-71.

6. Sutaria N, Northridge D, Shaw T. Significance of commissural calcification on outcome of mitral balloon valvotomy. Heart. 2000; 84: 398-402.

7. Salem DN, O'Gara PT, Madias C, SG P. Valvular and Structural Heart Disease, American College of Chest Physicians EvidenceBased Clinical Practice Guidelines (8th Edition). Chest. 2008 133:: 593S-629S.

8. Song H, Kang D, Kim J, Park K, Song J, Choi K, et al. Percutaneous Mitral Valvuloplasty Versus Surgical Treatment in Mitral Stenosis With Severe Tricuspid Regurgitation. Circulation. 2007; 116: I-246-I-50.

9. Ledesma MS, Gonzalez IC, Sanchez PL, Moreiras JM, Jneid H, Moreno PR, et al. Impact of concomitant aortic regurgitation on percutaneous mitral valvuloplasty: Immediate results, shortterm, and long-term outcome. Am Heart J 2008; 156: 361-6. 
Jurnal Kardiologi Indonesia

10. Sutaria N, Elder AT, TRD S. Long term outcome of percutaneous mitral balloon valvotomy in patients aged 70 and over. Heart. 2000; 83: 433-8.

11. de Souza JAM, Martinez EE J, Ambrose JA, Alves CMR, Born
D, Buffolo E, et al. Percutaneous balloon mitral valvuloplasty in comparison with open mitral valve commissurotomy for mitral stenosis during pregnancy. J Am Coll Cardiol 2001; 37: 900-3. 